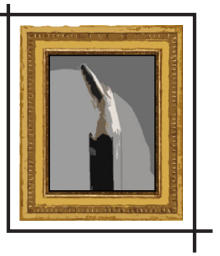

\title{
A VISUALIDADE NO MOVIMENTO PARANISTA: SÍMBOLOS DE UMA IDENTIDADE VISUAL
}

\author{
Arethusa Almeida de Paula* \\ Edemar José Baranek**
}

Resumo: Com a emancipação do Paraná perante o estado de São Paulo, em 1853, e a perda de parte do território paranaense para Santa Catarina na Disputa do Contestado (1912-1916), intensificou-se um movimento regionalista para construção identitária do estado, denominado de Movimento Paranista. Iniciado em 1899, com a publicação do livro História do Paraná por Alfredo Romário Martins, consolidou-se como movimento quando, em outubro de 1927, funda-se o Centro Paranista e publica-se o manifesto Paranismo. Nesse manifesto, o paranista é definido como todo aquele que tem pelo Paraná uma afeição sincera e que a demonstra em atividade digna e útil à coletividade paranaense. 0 movimento visava, assim, sedimentar suas ideias por meio da publicação de textos políticos e literários e pela eleição de símbolos visuais, destacadamente o pinheiro, a pinha e o pinhão, e posteriormente com a inclusão da gralha-azul. Destacaram-se artistas como Frederico Lange de Morretes (pintor, desenhista e gravador), João Zanin Turin (escultor) e João Zaco Paraná (pintor, desenhista e escultor) dentro do movimento, com exaustiva utilização de tais simbolos. Dessa maneira, o movimento criou ativamente uma identidade paranaense, sendo resultado da ação da literatura e, principalmente, da visualidade. A identidade paranaense, sua simbologia e seu reconhecimento foram gerados pela negação das diferenças em relação ao nacional, não sendo elementos naturais, mas construções culturais e sociais. Portanto, não se pode diminuir a influência das representações propagandeadas pelo Movimento Paranista na formação identitária e no imaginário social do estado, pois temos ainda no presente forte influência em discursos oficiais, elementos identitários e oficiais do Paraná, em monumentos históricos e nas artes visuais.

Palavras-chave: Paraná. Paranismo. Pinhão. Pinheiro. Romário Martins.

\section{INTRODUÇÃO}

Com a emancipação tardia da ainda capitania do Paraná perante a capitania de São Paulo, em 1853, pertencentes ao Brasil monárquico e a perda de parte do território paranaense para

\footnotetext{
* Doutora em Artes pela Universidade Federal de Minas Gerais (UFMG). Mestra em Estética e História da Arte pela Universidade de São Paulo (USP). E-mail: arethusadepaula@claretiano.edu.br

** Especialista em História da Arte pelo Centro Universitário Claretiano. Licenciado em Artes Visuais pelo Centro Universitário Internacional (Uninter).E-mail: edemar.baranek@uffs.edu.br
} 
o estado de Santa Catarina na Disputa do Contestado (1912-1916), intensificou-se um movimento regionalista - artístico, político e intelectual - para construção identitária do estado em oposição às outras regiões brasileiras, denominado de Movimento Paranista, numa postura de afirmação identitária positivista. Iniciado em 1899, com a publicação do livro História do Paraná por Alfredo Romário Martins, consolidou-se como movimento quando, em outubro de 1927, funda-se o Centro Paranista e publica-se o manifesto Paranismo. Nesse manifesto, o paranista é definido como todo aquele que tem pelo Paraná uma afeição sincera e que a demonstra em atividade digna e útil à coletividade paranaense, enfatizando a vocação trabalhadora da população que constituía o jovem estado. 0 movimento visava, assim, sedimentar suas ideias por meio da publicação de textos políticos e literários e pela eleição de símbolos visuais, destacadamente o pinheiro, a pinha e o pinhão, naquele momento.

Tratou-se de um movimento interno e regionalista ligado à criação identitária e de configuração geográfica estadual. Além da inserção dos imigrantes vindos ao estado, tinha como principais intentos a valorização do Paraná, por meio da divulgação de suas qualidades e idealizações de uma terra para o trabalho, que rumava ao progresso, com ordem, por meio da bondade e da justiça. Foi idealizado para forjar "uma identidade [...] a partir da demarcação de limites políticos-territoriais feita pelo Estado e pelas elites do poder" (CERRI, 2008, p. 33).

Consequência direta do simbolismo europeu, em voga nesse momento histórico na capital paranaense, adotava também os ideais republicanos, positivistas e anticlericais, amplamente divulgados no Brasil todo em função da campanha de independência brasileira, como fundamentação teórica para o desenvolvimento das ações do movimento.

Dessa maneira, buscando verificar se o Movimento Paranista auxiliou na criação de uma identidade paranaense, por meio de sua visualidade, elencando simbolos que sedimentaram a imagem do Paraná, desenvolveu-se este trabalho, que se insere na linha de pesquisa em teoria e história das artes visuais, utilizando levantamento de material bibliográfico, visando amparar a explicitação do objetivo proposto. Inicialmente, realizou-se uma pesquisa bibliográfica histórica, contextualizando o recorte histórico de 1927 - fundação do Centro Paranista e publicação do manifesto Paranismo - até 1931 - ano da extinção da revista Illustração Paranaense. Posteriormente, focaram-se os elementos visuais criados e disseminados pelo Movimento Paranista e as consequências destes na criação de uma identidade paranaense e possiveis desdobramentos dessa criação identitária.

\section{O MOVIMENTO PARANISTA E A IDENTIDADE PARANAENSE}

Alessandro Batistella $(2012$, p. 2) afirma que "o paranismo foi o resultado de um longo processo de formulação de uma autoimagem do estado do Paraná, em contraposição às 
outras regiões do Brasil". Esse processo de afirmação teve início com a emancipação política do estado em 19 de dezembro de 1853. Como destaca Cíntia Carneiro (2013, p. 65), "neste processo de construção de uma identidade para o Paraná destacava-se a valorização de elementos locais, do território paranaense e da história desta população".

Assim, o paranismo surge como um movimento regionalista, pois, segundo Luis Fernando Cerri (2008, p. 31), "a identidade é elemento central na composição das subjetividades e, por conseguinte, das ações e inações de cada um". Segundo Carneiro (2013, p. 80), nesse intento empregam-se "instrumentos como imagens, alegorias, símbolos, rituais e mitos, sinais importantes na construção de uma imagem". Para Luís Fernando Pereira (1996, p. 42), "imagens são produzidas, heróis são construídos", buscava-se uma tradição ritual e simbólica.

Tratou-se de um movimento interno, pois, como destaca Luciana Bueno (2009), foi uma reação aos seguintes fatos: o estado havia colaborado na Guerra do Paraguai (1864-1870), defendera a República no cerco da Lapa, em janeiro de 1894, por 26 dias (FERNANDES, 2007), e fora elemento forte na defesa de emancipação dos escravos. Além disso, Santa Catarina recebera os benefícios da conquista do território. Em 1901, Santa Catarina entrou no Supremo Tribunal Federal reivindicando o território da disputa do contestado, o que somente em 1916 viria a ser resolvido com a assinatura de um acordo entre os estados (FERNANDES, 2007; MUSSOI, 2015). Deve-se ainda considerar o fato de ter sido a última província emancipada da Quinta Comarca da Província de São Paulo (19 de dezembro de 1853), para deter o ímpeto separatista gaúcho (PEREIRA, 1996), portanto resultante de características explicitamente históricas (CARNEIRO, 2013; FERNANDES, 2007; OLIVEIRA, 2005; PEREIRA, 2005).

"Longe de ser simbolizado apenas pela capital, o Paraná deve ser lembrado pela pluralidade dos grupos que o formaram e pela busca da equidade e do reconhecimento dos novos sujeitos pelas inúmeras contribuições que o construiu" (SILVA; FERNANDES, 2008, p. 123). Desse modo, esse movimento regionalista, para além da inserção dos imigrantes vindos ao estado, tinha como principais intentos a valorização do Paraná, por meio da divulgação das qualidades e idealizações de uma terra para o trabalho, que rumava ao progresso, com ordem, por meio da bondade e da justiça (BUENO, 2009; CARNEIRO, 2013; FERNANDES, 2007).

Segundo Pereira (1996) e Salturi (2009), vários intelectuais, políticos e artistas no final do século XIX e início do XX foram influenciados pelos ideais e trabalhos de Romário Martins na "invenção de uma tradição paranaense" (BATISTELLA, 2012). De acordo com Pereira (2005, p. 25), "toda a fragilidade do Estado em termos de construção de uma identidade regional e a inexistência de uma história vigorosa [...] [conduziram] os pensadores paranistas no sentido de preencher essas lacunas".

Por sua trajetória, Martins dedicou-se à divulgação do folclore e da história estadual: publicou, em 1899, o livro História do Paraná, participou da fundação, em 1900, do Instituto Histórico e Geográfico do Paraná e foi o principal fundador do Centro Paranista em 1927. Entre suas pesquisas, destacam-se questões dos limites entre os estados do Paraná e de 
Santa Catarina. Elaborou algumas leis, como as referentes à criação do brasão e da bandeira do estado do Paraná.

No entanto, atualmente Romário Martins é considerado um "historiador historicista", um criador - forjador - de símbolos, conforme trabalho de Décio Szvarça (1993). Segundo esse autor, Romário conta uma história de dominadores, descontínua, e, para preencher essa descontinuidade, teria forjado um conjunto de símbolos e mitos que permitiram criar uma imagem ideal da identidade estadual à qual todos deveriam integrar-se. Para Pereira (1996, p. 61), "o importante era não retratar a realidade, mas construir uma imagem do real que, por sua força simbólica, se tornaria mais forte que o próprio real". Assim, a construção da memória se faz pelo acúmulo de imagens (PEREIRA, 1996).

De acordo com Salturi (2009), a questão identitária local foi tratada inicialmente no artigo "Paranística", em que são apresentados os termos paranismo e paranista. Sobre essa temática, Romário relata que o vocábulo paranista foi usado pela primeira vez, em 1906, pelo escritor Domingos Nascimento depois de viagem realizada ao norte do estado, quando notara que ninguém se chamava de paranaense, mas sim paranista. Dessa forma, a palavra teria origem espontânea e ganhou novo significado por Romário, em 1927, quando da criação do Centro Paranista e da publicação do manifesto Paranismo (OLIVEIRA, 2005; SALTURI, 2009).

Para criação de um imaginário popular, o Movimento Paranista utilizou-se das artes visuais com o intuito de alfabetização visual não formal, ou seja, não escolar. Decorações, icones e toda sorte de objetos visuais foram espalhados, principalmente na capital, Curitiba, para convencer a população de que, a partir de então, o pinheiro, a pinha e o pinhão eram efetivamente símbolos do estado do Paraná (BUENO, 2009; CARNEIRO, 2013; PEREIRA, 1996). Oliveira (2005, p. 37) afirma que "até uma moda paranista foi pensada pelo artista João Turin", concordando com Pereira (1996). Tais informações são corroboradas por Anne Cauquelin (2005, p. 162): "a atividade artística sempre foi requisitada pelo poder para dar visibilidade aos conceitos que lhe servem de princípios"; portanto, os símbolos têm a função pedagógica da construção de uma história regional, uma tradição (PEREIRA, 1996).

Uma importante fonte de divulgação dos pensamentos, das ideias e da visualidade do Movimento Paranista foi a revista Illustração Paranaense, que circulou entre 1927 e 1930 (BATISTELLA, 2012; BUENO, 2009; OLIVEIRA, 2005; PEREIRA, 1996; SALTURI, 2009). Importante veículo de divulgação da produção imagética do movimento paranista, foi a fonte da propagação da estilização do pinheiro e de seus frutos, por Lange de Morretes, reconhecidos até o presente (PEREIRA, 1996).

Dentro do movimento, a atuação da revista foi extremamente significativa: um "período de 'vida ativa' determinado ao movimento foi exatamente durante a circulação da mesma" (BUENO, 2009, p. 33). Portanto, pode-se considerar que o Movimento Paranista tem seu término em torno de 1931, porém não o paranismo e sua visualidade. 
É relevante esclarecer que o Paranismo é consequência direta do Simbolismo, pois o primeiro estende os ideais republicanos, positivistas e anticlericais do simbolismo curitibano no plano das artes visuais. Paranismo e simbolismo são ainda mais consoantes, pois a ideia simbolista transplantada para as artes plásticas se revelará por signos da realidade que deseja construir (BUENO, 2009, p. 38).

Romário Martins, ao idealizar o paranismo, identificava-se com o simbolismo, o nacionalismo, o positivismo e o anticlericalismo - movimentos existentes no início do século XX entre a intelectualidade brasileira -, e essa particularidade, aliada à necessidade da criação de uma identidade local, acabou desvinculando o estado do conceito do tropical e, consequentemente, do movimento modernista brasileiro. Assim, os elementos iconográficos do paranismo foram criados em uma linguagem regional de forte teor panfletário para o estímulo do local (CAMARG0, 2007; CARNEIRO, 2013; OLIVEIRA, 2005; PEREIRA, 1996).

Segundo Carneiro (2013, p. 77), "o nacionalismo foi uma forte característica do periodo republicano, pois como não houve uma participação popular na proclamação da República [...], surgiu a necessidade em legitimar e consolidar a nova forma de governo". Quanto ao positivismo, ele surge como ideologia para legitimação do regime político.

Bueno (2009) e Carneiro (2013) relatam que os símbolos paranistas atuantes na produção visual de artistas locais, além de outras peças como os manifestos, as revistas e os poemas com suas ilustrações, cravaram suas raízes no imaginário popular, como previam os idealizadores do movimento. Porém, não se pode ter certeza que tenha criado ramificações a ponto de ser reconhecido em todo o estado, visto que era um movimento marcadamente da capital, todavia até hoje seus simbolos fazem-se presentes.

Porém, há que se pontuar que

[...] a arte não pode mudar o mundo, mas pode modificar as consciências e as pulsões dos homens e é exatamente neste sentido que a mesma será utilizada pelos paranistas; no sentido de modificar a consciência da heterogênea população que habitava as terras paranaenses, para que a mesma passasse a ver na República um modelo que trouxesse um desenvolvimento para a região e, mais do que isto, para a construção de um sentimento de pertencimento ao Estado (PEREIRA, 1996, p. 159).

Destacam-se entre os artistas representantes do paranismo Frederico Lange de Morretes, João Turin, Alfredo Andersen, Theodoro de Bona, João Ghelf, Kurt Freysleben, Stanislau Traple, Zaco Paraná (BUENO, 2009; CARNEIRO, 2013; SALTURI, 2009), entre outros, na exaustiva utilização de tais símbolos, o pinheiro - transfigurado no símbolo verde das esperanças -, a pinha e o pinhão, mas também as paisagens e a população paranaense, "temas locais da flora, da fauna e do indigena, tanto nas artes plásticas, quanto nas artes gráficas e decorativas" (SALTURI, 2009, p. 9). 
Além dos "tradicionais" pinheiro, pinha e pinhão usados como elementos gráficos (BUENO, 2009), utilizaram-se "a palmeira, a guabiroba, a pitanga, o maracujá, o café, a erva-mate e também a gralha-azul" (SALTURI, 2009, p. 11). A gralha-azul tornou-se a ave símbolo do estado em 12 de novembro de 1984, por meio da Lei Estadual n. 7.957 (BUENO, 2009).

Mesmo na capital existiam vozes dissonantes quanto a um ambiente que repetia sempre "que o mais importante seria mostrar o amor pelo Paraná, pelos pinheiros, sua geografia, suas belas praias, seus homens proeminentes" (OLIVEIRA, 2005, p. 5), buscando novas fontes no modernismo. 0 paranismo está mais preocupado com a fixação de um padrão estético a ser reproduzido do que com qualidade artística e renovação (OLIVEIRA, 2005).

Assim, apesar da intensa efervescência cultural (PEREIRA, 1996), artística e política na capital, o interior do estado, principalmente o oeste paranaense, vivia uma situação de abandono e desnacionalização em relação às demais regiões do Paraná (Zatti, 2014; Rosevics, 2016). Como relata Mussoi (2002, p. 74), "os combates da revolução de 1924 travados no oeste do Paraná, serviram para mostrar ao Brasil toda essa situação". Além disso, segundo Oliveira $(2005$, p. 6), "o movimento tinha pouca penetração no interior e pouca repercussão fora" do estado.

Assim, tentando minimizar tal situação de abandono e visando garantir a soberania nacional, Getúlio Vargas assina, em 13 de setembro de 1943, o Decreto-Lei n. 5.812 que cria o território e define seus limites sem, contudo, determinar sua capital. Então, após uma semana, em 21 de setembro, Vargas estabelece, por meio do Decreto-Lei n. 5.839, que a capital do território do Iguaçu seria a cidade de igual nome.

No entanto, não existia à época, dentro dos limites do território, cidade com tal nome, o que levou os habitantes a crer que Foz do Iguaçu seria a capital do novo território federal. A dúvida durou oito meses, até um novo decreto, n. 6.550, de 31 de maio de 1944, definir "que a capital era Iguaçu, ex-vila Xagú e ex-Laranjeiras, por ser mais próximo a civilização" (MUSSOI, 2002, p. 76), atualmente município de Laranjeiras do Sul.

A criação do novo território levou o estado do Paraná a perder parte de sua área, o que não agradou aos políticos e intelectuais da capital paranaense, Curitiba, que lutavam para configuração de uma unidade estadual (MUSSOI, 2015; SALTURI, 2009). Há vários exemplos de insatisfação, como a publicação pelo jornal Gazeta do Povo de Curitiba, nas edições de 25, 27, 28, 29 e 30 de agosto e $1^{\circ}$ de setembro de 1931, de parecer repudiando a criação do Território Federal do Iguaçu e muitos outros documentos (MUSSOI, 2015). Assim, com o término do regime do Estado Novo de Getúlio Vargas, em 1945, e uma nova Constituição para o país sendo votada,

[...] as forças políticas paranaenses resolveram aproveitar esta oportunidade para se mobilizar e, através da própria constituição, extinguir o Território Federal do Iguaçu com o consequente retorno das áreas perdidas com a sua criação aos estados de origem (Paraná e Santa Catarina) (MUSSOI, 2002, p. 77). 
Em 18 de setembro de 1946, o Território Federal do Iguaçu foi extinto, voltando suas áreas a pertencer aos estados que originalmente as constituíam (MUSSOI, 2002). 0 regionalismo paranaense foi influenciado pelo paranismo no início do século XX e, após 1945, marcado por diferentes características na configuração ideológica, visando "garantir a reprodução de interesses dominantes através do controle do aparelho jurídico-político do Estado" (SALTURI, 2009, p. 16).

Para compreensão desse movimento de arte local, distinto do modernismo que crescia em outras regiões do país, deve-se considerar o que relata Cerri $(2008$, p. 39) sobre a história local ante a nacional:

[...] o que ocorre é que há uma determinada história local que se abriga sem problemas debaixo da sombra da história nacional, assumindo seu papel subordinado em uma identidade planejada e executada de cima para baixo, que se centraliza em uma memória, antes que em uma história. Essa história local miniaturiza a tradição da história nacional e escolhe seus próceres, símbolos e espaços consagrados, e sincroniza o tempo de seus objetos locais com o tempo da história nacional, herdando os pressupostos e as limitações desta última.

Aliado a isso, parte-se da premissa de que "a imagem enquanto documento não deve ser considerada como mera ilustração de um texto escrito" (MOLINA, 2008, p. 68). Os repertórios, de quem produz e de quem recebe a imagem, influenciam na interpretação de imagens, pois estão atreladas a fatores que transcendem a informação direta que se é apresentada pela imagem e a capacidade da percepção do receptor: "Entram em jogo o saber, os afetos, as crenças, que, por sua vez, são muito modelados pela vinculação a uma região da história (a uma classe social, a uma época, a uma cultura)" (AUMONT, 1993, p. 77).

Molina (2008, p. 68) complementa a ideia de Aumont (1993) quando relata o seguinte:

[...] além do seu cunho "conteudista" devemos refletir sobre as diversas linguagens em cena, a produção e as diferentes faces e interfaces desse conjunto de visualidades [...] que propõem mediações entre o mundo e seu observador, operadas por registros gráficos, e também modos como esse mundo visto foi organizado, considerando também a posição do observador que envolve o processo de seleção e recorte de uma cena.

A imagem apresenta significância nas relações da comunicação humana, ganhando relevância ao ser realocada do seu espaço de origem para distâncias geográficas distintas, levando narrativas, conceitos, informações, emoções e cultura, e criando emoções das mais diversificadas (AUMONT, 1993; DONDIS, 1991). 


\section{CONSIDERAÇÕES FINAIS}

Atualmente, os símbolos do paranismo continuam sendo amplamente utilizados em todo o estado, seja em representações oficiais, seja em representações da cultura local popular, provando que as dimensões estéticas e simbólicas criaram um terreno comum de identificação, gerando uma identidade cultural para um estado que na época de sua emancipação sequer tinha suas fronteiras definidas (PEREIRA, 1996). Segundo Zatti (2014) as escolas paranaenses continuam reproduzindo um conhecimento imagético relacionado ao Movimento Paranista, sem, no entanto, contextualizar historicamente suas origens.

Entretanto, a história sobre o Movimento Paranista é desconhecida de grande parcela da população, em um paradoxo de adoção do simbolismo visual, mas desconhecimento de suas origens. Isso demonstra, como destaca Pereira (1996, p. 94), que é necessário um aprofundamento nas "investigações sobre as perspectivas e possibilidades da arte, sobre a relação da estética com a ética e com a política".

\section{Visuality in the Paranista Movement: symbols of a visual identity}

Abstract: The emancipation of Paraná State from the State of São Paulo, in 1853, and the loss of part of the territory of Santa Catarina in the Brazil's Contestado Rebellion (1912-1916), a regionalist movement for construction of a state identity was intensified, called Paranista Movement. Started in 1899, with the publication of the book History of Paraná by Alfredo Romário Martins, it consolidated as a movement when in October 1927 the Paranista Center was founded and the Paranismo manifesto was published, defining in this the paranista as being all that has at least Paraná a sincere affection, and that demonstrates in a dignified, useful activity to the paranaense collectivity. The movement aimed to sediment its ideas through the publication of political and literary texts and the election of visual symbols, notably pine, pine cone and pinion fruit, and later including the blue crow. Artists such as Frederico Lange de Morretes (painter, draftsman and engraver), João Zanin Turin (sculptor) and João Zaco Paraná (painter, drawer and sculptor) were prominent within the movement, with exhaustive use of such symbols. In this way, the movement actively created an identity of Paraná, being a result of the action of literature and, mainly, of visuality. The identity of the state of Paraná, its symbology and its recognition were generated by the denial of differences in relation to the national, not being natural elements, but are cultural and social constructions. Therefore, it is not possible to diminish the influence of the representations propagated by the Paranista Movement in the identity formation and in the social imaginary of the state, since we still have in the present strong influence in official discourses, identity elements and state officials, in historical monuments and in the visual arts.

Keywords: Paraná. Paranismo. Pine. Pinion fruit. Romário Martins. 


\section{REFERÊNCIAS}

AUMONT, J. A imagem. Campinas: Papirus, 1993.

BATISTELLA, A. 0 paranismo e a invenção da identidade paranaense. Revista Eletrônica História em Reflexão, Dourados, v. 6, n. 11, p. 1-13, jan./jun. 2012.

BUENO, L. E. B. 0 paranismo e as artes visuais. 2009. 173 f. Dissertação (Mestrado em Artes Visuais) - Universidade do Estado de Santa Catarina, Florianópolis, 2009.

CAMARGO, G. L. V. de. Paranismo: arte, ideologia e relações sociais no Paraná. 1853-1953. 2007. 215 f. Tese (Doutorado em História) - Universidade Federal do Paraná, Curitiba, 2007.

CARNEIRO, C. B. O Museu paranaense e Romário Martins: a busca de uma identidade para o Paraná. Curitiba: Samp, 2013. 202 p.

CAUQUELIN, A. Arte contemporânea: uma introdução. São Paulo: Martins Fontes, 2005.

CERRI, L. F. Cidade e identidade: região e ensino de história. In: ALEGRO, R. C. et al. (Orgs.). Temas e questões para o ensino de história do Paraná. Londrina: Eduel, 2008. p. 27-42.

DONDIS, D. A. Sintaxe da linguagem visual. São Paulo: Martins Fontes, 1991.

FERNANDES, V. B. O Paraná é assim. 3. ed. Curitiba: V. B. Fernandes, 2007. 122 p.

MOLINA, A. H. Mapas históricos: alguns apontamentos e uma abordagem pedagógica. In: ALEGRO, R. C. et al. (Orgs.). Temas e questões para o ensino de história do Paraná. Londrina: Eduel, 2008. p. 68-86.

MUSSOI, A. B. Laranjeiras do Sul: o espaço em construção. Cascavel: Edunioeste, 2002. 174 p.

MUSSOI, A. B. Território Federal do Iguaçu: perspectivas para o desenvolvimento regional. Laranjeiras do Sul: Cantu, 2015. 183 p.

OLIVEIRA, L. C. S. de. Joaquim contra o paranismo. 2005. 234 f. Dissertação (Mestrado em Estudos Literários) - Universidade Federal do Paraná, Curitiba, 2005.

PEREIRA, G. Bento Mossurunga e o movimento paranista. Estudo histórico-analítico das obras para canto e piano e piano solo compostas nas décadas de 1930, 40 e 50. 2005. $73 \mathrm{f}$. Dissertação (Mestrado em Música) - Universidade Federal do Rio Grande do Sul, Porto Alegre, 2005.

PEREIRA, L. F. L. Paranismo: cultura e imaginário no Paraná da I República. 1996. 276 f. Dissertação (Mestrado em História) - Universidade Federal do Paraná, Curitiba, 1996.

ROSEVICS, L. Os primeiros anos do Instituto Histórico e Geográfico do Paraná (1900-1930). Revista Núcleo de Estudos Paranaenses, Curitiba, v. 2, n. 3, p. 38-50, jun. 2016. 
SALTURI, L. A. Frederico Langes de Morretes, liberdade dentro de limites: trajetória do artista cientista. 2007. 268 f. Dissertação (Mestrado em Sociologia) - Universidade Federal do Paraná, Curitiba, 2007.

SALTURI, L. A. Paranismo, movimento artístico do sul do Brasil no início do século XX. Periféria: Revista de Recerca i Formació em Antropologia, Barcelona, v. 11, p. 1-22, 2009.

SILVA, L. H. 0.; FERNANDES, P. M. Etnias do Paraná. In: ALEGRO, R. C. et al. (Orgs.). Temas e questões para o ensino de história do Paraná. Londrina: Eduel, 2008. p. 113-126.

SZVARÇA, D. R. 0 forjador: ruínas de um mito - Romário Martins: 1893-1944. 1993. 162 f. Dissertação (Mestrado em História) - Universidade Federal do Paraná, Curitiba, 1993.

ZATI, C. O Paraná e o paranismo. 2. ed. Curitiba: Clube dos Autores, 2014. 207 p. 